\title{
Intrahepatic Cholestasis of Pregnancy with Marked Elevation of Transaminases in a Black American
}

\author{
JOANNE A.P. WILSON, MD, FACP \\ KEY WORDS: cholestasis; pregnancy; jaundice of pregnancy; hypertransaminasemia.
}

Intrahepatic cholestasis of pregnancy (ICP) is a rare disorder. It has most frequently been reported from Chili, Scandanavia and, less frequently, the United States (1-3). It has not previously been reported in black women (4). The incidence is reported to be from 1 in 750 to 1 in 8000 gestations $(2,5)$. The disorder is felt to be entirely benign to the mother and is not associated with residual liver damage. It is characterized by pruritis with mild bilirubin elevation and mild transaminasemia. Both pruritis and jaundice disappear rapidly after delivery. Differentiation of this entity from other disorders that may cause jaundice during pregnancy is important. Viral hepatitis is the most common cause in this country $(6,7)$. Prenatal diagnosis of hepatitis B is particularly important, since treatment of infants at birth can prevent neonatal hepatitis (8). The differentiation of viral hepatitis from ICP is usually not difficult. However, some cases of ICP have been reported in which transaminases are markedly elevated, causing confusion with actute viral hepatitis (9). We report here a case of intrahepatic cholestasis of pregnancy in a black woman that was associated with marked elevation of transaminases and moderate signs of cholestasis.

Manuscript received June 21,1985 ; revised manuscript received Decomber 19, 1985; accepted April 30, 1986.

From the Department of Internal Medicine, Gastroenterology, University of Michigan Medical Center, Ann Arbor, Michigan 48109 .

Mddress for reprint requests: Dt. Joanne A.P. Wilson, 3912H Taubman Center, Box 0362, Lniversity of Michigan Medical Center, Ann Arbor, Michigan 48109.

\section{CASE REPORT}

The patient was a 36 -year-old black health-care professional gravida 4 para 3 who presented with severe pruritis and mild nausea of approximately 1 week duration. The patient was at 38 weeks gestation, and her pregnancy had been without complications. She had severe generalized pruritis including the palms and soles. Pruritis was particularly prominent at night. She had noted mild nausea (without emesis or anorexid), darkening of urine, and lightening of stool. She had no abdominal pain, fever, malaise, skin rash, arthralgias, or adenopathy. She had a past medical history of hypertension with her first ful1term pregnancy, but without significant proteinuria or other signs of toxemia. Neither previous oral contraceptive therapy nor previous pregnancies were associated with pruritis or jaundice. She had no history of liver disease, needle stick, or blood transfusion, and had had previous negative bepatitis B serologies. She had no family history of liver disease, pruritis, or jaundice associated with pregnancies. Her medications included prenatal vitamins and iron.

Physical examination was remarkable for a normal fundoscopic examination, and the absence of scleral icterus, spider angiomata, or other stigmata of chronic liver disease. She had trace pedal edema. Neurological examination was normal. The uterus was consistent with gestational date and good fetal heart tones were noted. Routine laboratory studies showed a normal hematocrit of $40 \%$ with a white blood cell count of 7300 and normal platelet count. Bilirubin, transaminases, and alkaline phosphatase were elevated as indicated in Table 1. Urinalysis revealed trace biliubin, but no protein, gilucose, or ketones. Prothrombin time and partial thromboplastin time werc normal. Hepatitis B surface antigen, surface antibody, and core antibody were negative. Hepatitis $A$ antibody (IgM) was negative. Serology for CMV, toxoplasmosis, herpes, and rubella were unremarkable.

The patient's course was characterized by continued prurits and increasing bilirubin without other symptoms. Blood pressure was noted to be elevated at $120 / 85$ one 
Tabie 1. Laboratory Data

\begin{tabular}{|c|c|c|c|c|c|c|c|c|c|}
\hline & \multicolumn{9}{|c|}{ Date } \\
\hline & 715 & 77 & $7 / 9$ & $7 / 11^{*}$ & $7 / 12$ & $7 / 14$ & $7 / 16$ & $7 / 27$ & $9 / 28$ \\
\hline$\underset{\mathrm{IU} / \text { liter) }}{\mathrm{GOT}(\mathrm{AST})(2-35}$ & 268 & 332 & 249 & 297 & 207 & 97 & 62 & 33 & 18 \\
\hline $\begin{array}{l}\text { GPT (ALT) (2-35 } \\
\text { IU/liter) }\end{array}$ & 600 & 715 & 615 & 610 & 497 & 338 & 241 & 43 & 27 \\
\hline $\begin{array}{c}\text { Alkaline phosphatase } \\
\text { (30-96 JU/liter) }\end{array}$ & 283 & 291 & 294 & 289 & 238 & 220 & 204 & 130 & 96 \\
\hline GGTP (1-35 IU/liter $)$ & & 40 & 38 & 40 & & & & 32 & 28 \\
\hline Bilirubin $(0.1-0.9 \mathrm{mg} / \mathrm{d})$ & 0.7 & 1.1 & & 1.3 & 0.7 & 0.6 & 0.7 & 0.7 & 0.6 \\
\hline Cholylglycine $(0-40 \mu \mathrm{g} / \mathrm{d} 1)$ & & 900 & & & & & & 29.7 & \\
\hline
\end{tabular}

*Delivered on July 11 .

day prior to induction. Urine remained free of protein. Delivery was induced by pitocin without complications. The 3750-gram female infant was healthy with an Apgar of 9 at $5 \mathrm{~min}$. The patient had a rapid decrease in pruritis with resolution by day 4 postpartum. Enzymes dropped rapidly as indicated in Table 1 . Her postpartum course was complicated by endometritis which tesponded well to antibiotic therapy. During 6-month follow-up, she has had no further symptoms, gallbladder ultrasound was normal, and her enzymes have returned to normal. Antimitochondrial antibody was negative.

\section{DISCUSSION}

This case illustrates many of the classic features of intrahepatic cholestasis of pregnancy. The patient had the onset of her symptoms late in pregnancy. This pattern has been observed in most of the reported cases $(1,2,4,5,7)$, although some patients have had symptoms as early as the sixth week of gestation (7). Pruritis is the predominant symptom in most patients, as was the case in this patient. Jaundice may not occur. However, when it does, it follows the onset of pruritis by one to two weeks extending up to 22 weeks $(2,7)$. Our patient had a slow rise in her bilirubin without icterus. Darkening of urine and lightening of stool are seen in some of the patients and usually precedes clinical jaundice (7). The paucity of other symptoms and signs are a hallmark of this disorder, in particular the absence of biliary colic, fever, and general malaise $(4,7)$. The rapid resolution of symptoms with delivery is expected. In almost all cases, pruritis resolves by two weeks postpartum, with most clearing in the first week.

In most cases, the biochemical features present are those of cholestasis. Alkaline phosphatase is usually elevated but may fall in the range of that seen in normal pregnancy (7). Our patient had moderate elevation of alkaline phosphatase. This enzyme has been reported to fall slowly after delivery and, as in this case, may be the last to return to normal $(2,7)$. Gammaglutamyltranspeptidase (GGTP) was elevated in this case. This enzyme is particularly useful during pregnancy, since it is elevated with cholestasis and is not affected by pregnancy (10). Serum bile acids are very sensitive indicators of cholestasis. Serum bile acids, especially cholic acid, are significantly greater in ICP than in normal pregnancy (11) and correlate with pruritis better than bilirubin and alkaline phosphatase (9). The patient had cholic acid elevated $>20$ fold, which rapidly returned to normal after delivery.

One of the unusual aspects of this case is the occurrence of ICP in a black American, which has not been reported previously (4). ICP has been reported in Europe, North and South America, and Australia, however the disorder is rare, with incidence estimated at from 1 in every $750-8000$ gestations (1-3). Much higher incidences are reported in the Scandinavian countries, Poland, and Chile, the latter having the highest rates (one case in every ten gestations) in some areas of the country (12). Studies in Chile (13) and in other countries $(14,15)$ suggest genetic factors with inheritance in a sexlimited, Mendelian dominant pattern. No linkage with HLA histocompatibility antigens has been demonstrated. The disorder is associated with sensitivity to ethinyl estradiol, resembling symptoms encountered with pregnancy $(16,17)$. This response can serve as a possible screening study for demonstration of the trait.

The patient in this report had had no symptoms with two previous full-term pregnancies and oral contraceptive therapy. Multiparous women may display marked variation in the onset and severity in each gestation. Frequently patients will have one 
or more asymptomatic pregnancies before ICP occurs. However, subsequent pregnancies will usually be affected, although severity may vary (2).

Marked elevation of transaminases was noted in this patient. The serum glutamic pyruvic transaminase (SGPT, alanine aminotransferase) was $\sim 20$ fold elevated. This is in comparison with serum glutamic oxaloacetic transaminase (SGOT, aspartate aminotransferase), which was only eightfold elevated. This pattem raises the question of viral hepatitis, particularly since (1) the patient was a health-care professional, (2) viral hepatitis is the most common cause of jaundice in pregnancy in this country, and (3) transaminases are usually less than 200 in $\operatorname{ICP}(5,7,9)$.

It is now important to diagnose viral hepatitis $B$ because transmission to the child can be prevented by hepatitis $B$ immune serum globulin and hepatitis $B$ vaccination (8, 18, 19). Acute non-A, non- $B$ hepatitis is a possibility in this case, and it cannot definitely be eliminated. Serological tests are not available, and liver histology was not performed. Perhaps the effect of estrogenic hormones may have induced a disproportionately cholestatic picture (7). The cholestatic state of the last trimester of pregnancy is demonstrated by the increased bromosulphthalein (BSP) retention due to a reduction of BSP secretion into bile (20). The course of viral hepatitis in pregnancy is generally not different from that in nonpregnant women in the Western countries $(6,7$, 16. In India, Africa, and the Middle East, the severity of acute viral hepatitis increases during pregnancy $(6,7,21)$. A recent study from India reported an increased incidence of non-A, non-B hepatitis during pregnancy with an increased incidence of fulminant hepatitis during the third trimester (21). Malnutrition has been suggested as a cause for the severity of hepatitis in these countries (5-7). However, in this patient, viral hepatitis was unlikely in view of the lack of constitutional symptoms, negative serologies [hepatitis B surface antigen and antibody, hepatitis B core antibody, and hepatitis A (IgM) antibody], markedly elevated serum bile acid, and very rapid decline in serum transaminases in the immediate postpartum period.

Hepatic abnormalities have also been noted with toxemia of pregnancy $(5,22)$. These abnormalities are usually associated with disseminated intravascular coagulopathy which has been shown to result in venous thrombi, hemorrhage, fibrin deposition, and cell necrosis $(22,23)$. The spectrum is quite variable. Although this patient had mild hyperten- sion, she had no evidence of eclampsia or preeclampsia and had normal platelet count and coagulation parameters.

Chronic liver disease, such as primary biliary cirrhosis ( $\mathrm{PBC}$ ), might be considered in this patient. $\mathrm{PBC}$ may appear during the last trimester of pregnancy, where it presumably adds an additional cholestatic factor to that seen in normal pregnancy, as noted above $(20,24)$. The resultant cholestatic picture could mimic ICP. However, pruritis associated with $\mathrm{PBC}$ usually persists after delivery, although it may resolve and reappear later $(24,25)$. PBC is unlikely in this case since pruritis disappeared, alkaline phosphatase returned to normal, and the antimitochondrial antibody was negative.

The infant in this case suffered no untoward effects. Until recently, the clinical course of ICP was generally expected to be benign for both mother and child. However, several reports suggest that ICP is associated with an increased incidence of premature delivery and stillbirths $(9,26,29)$. Placental studies in ICP reveal some nonspecific changes that may contribute to fetal hypoxia and distress. Elevated maternal serum bile acids result in elevation in fetal serum and may mediate feta] distress (28).

This case illustrates several classic features of ICP, including onset and clinical course; however, it emphasizes some of the less common aspectsoccurrence in a black American, onset in a later pregnancy in a multiparous woman, and a biochemical pattern of markedly elcvated transaminases.

\section{SUMMARY}

A case of intrahepatic cholestasis of pregnancy (ICP) in a black American is presented. This is the first case reported in a black. Marked elevation of transaminases with mild biochemical evidence of cholestasis wàs initially suggestive of viral hepatitis. A clinical course characterized by pruritis with minimal constitutional symptoms, rapid resolution of biochemical abnormalities after delivery, and negative hepatitis A and B serologies was consistent with the diagnosis of ICP. Review of the classic features of ICP with emphasis on some unusual aspects of the disorder is included.

\section{ACKNOWLEDGMENTS}

Thanks are due to Dr. Mangaladevi Menon for obstetric care of the patient and Dr. Jorge Gumucio for advice on the case. 


\section{REFERENCES}

1. Svarborg A: A study of recurtent jaundice in pregnancy. Acta Obstet Gynecol Scand 33:434 444, 1954

2. Haemmerli UP, Wyss HI: Recurrent intrahepatic cholestasis of pregnancy-report of cases and review of the Hiterature. Medicine 46:299-321, 1967

3. Wilson BRl, Haverkamp AD: Cholestatic jaundice of pregnancy: New perspectives. Obstet Gynecol 54:650-652, 1979

4. Reyes H: The enigma of intrahepatie cholestasis of pregnancy: Lessons from Chile. Hepatology 2:87-96, 1982

5. Steven MM: Pregnancy and liver disease. Gut 22:592-614, 1981

6. Holbach T: Jaundice in pregnancy. Am J Med 61:367-376, 1976

7. Krejs GJ, Haemmerli UP: Jaundice during pregnancy. In Diseases of the Liver, 5 th ed. L Schiff, E Schiff (eds). Philadelphia, JB Lippinoott, 1983, pp 1561-1580

8. Beasley RP, Lee GC, Roan CH, Hwang LY, Lan CC, Huang FY, Chen CL: Prevention of perinataly transmitted hepatitis $B$ virus infections with hepalitis $B$ immune globulin and hepatitis vaccine. Lancet 2:1099-1102, 1983

9. Laatikainen T: Ikonen $E$ : Serum bile acids in cholestasis of pregnancy. Obstet Gynecol 50:313-318, 1977

10. Walker FB, Holit DL, Cunningham FG: Gamma glutanyl transpeptidase in normal pregnancy. Obstet Gynecol $43: 745-749,1974$

11, Laatikainen T: Postprandial serum bile acids in cholestasis of pregnancy. Ant Clin Res 10:307-312, 1978

12. Reyes H, Gonzalez MC, Ribalta J, Aburto H, Matus C, Schramm G, Katz R, Medina E: Prevalence of intrahepatic cholestasis of pregnancy in Chile. Ann Intern Med $88: 487-493,1978$

13. Reyes $H$, Ribalta J, Gonzalez-Ceron $M$ : ldiopathic cholestasis of pregnancy in a large kindred. Gut 17:709-713, 1976

14. Dalen $E$, Westerholm B: Occurrence of hepatic involvement in women jaundiced by oral contraceptives and in their mothers and sisters. Acta Med Scand 195:459-463, 1974

15. Holzbach RT, Silak DA, Braun WE: Familial recurrent intrahepatic cholestasis of pregnancy: A genetic study pro- viding evidence for transmission of a sex-limited, dominant tract. Gastroenterology 85:175-179, 1983

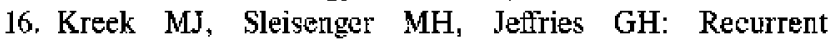
cholestatic jaundice of pregnancy with demonstrated estrogen sensitivity. Am J Med 43:795-798, 1967

17. Reyes H, Ribalta J, Gonzalez MC, Segovia N, Oberhauser E: Sulfobromophthalein clearance tests before and after ethinyl estradiol administration in women and men with fumilial history of intrahepatic cholestasis of pregnaney. Gastroenterology 81:226-231, 1981

18. Stevens CE, Beasley RP. Tsui J. Lee WC: Vertical transmission of hepatitis $B$ antigen in Taiwan. $N$ Engl $J$ Med 292:771-774, 1975

19. ACIP; Postexposure prophylaxis of hepatitis B. Morbidity and Mortality Weekly Report 33:285-290, 1984

20. Combes B, Shiba1a H, Adams RH, Mitchell B, Tramme V: Alterations in sulfobromophthalein sodium removal mechanisms from blood during normal pregnancy. J Clin Invest 42:1431-1442, 1963

21. Khuroo MS, Teli MR, Skidmore S, Sofi MA, Khuroo MI: Incidence and severity of viral hepatitis in pregnancy. Am J Med 70:252-255, 1981

22. Long RG, Scheuer PJ, Sherlock S: Preeclampsia presenting with deep jaundice. J Clin Pathol 30212-215, 1977

23. Riely CA, Romero R, Duffy TP: Hepatic dysfunction disseminated intravascular coagulation in toxemia of pregnancy-a distinct clinical syndrome. Gastroenterology 80-1346, 1981

24. Sherlock S: Primary biliary cirrhosis. In Liver and Biliary Disease. R Wright, KGMM Alberti, \$. Kartar, GH Millward-Sadler (eds). Philadelphia, WB Saunders, 1979, p 719

25. Sherlock S: Jaundice in pregnancy. Br Med Bull 24:39-43, 1968

26. Laatikainen TJ: Fetal bile acid levels in pregnancies complicated by matemal intrahepatic cholestasis. Am J Obstet Gyyecol 122:852-856, 1975.

27. Reid R, Ivey KJ, Rencoret RH, Storey B: Fetal complications of obstetric cholestasis. Br Med J 1:870-872, 1976

28. Laatikainen TJ, Peltonen JI, Nylander PL: Effect of maternal intrahepatic cholestasis on fetal steroid metabolism. J Clin Invest 53:1709-1715, 1974 